\title{
Epidemia midiática: produção de sentidos e configuração social da febre amarela na cobertura jornalística, 2007-2008
}

I ' Cláudia Malinverni, '2Angela Maria Belloni Cuenca,

3 Jacqueline Isaac Machado Brigagão I

Resumo: O objetivo deste artigo, situado no campo da comunicação em saúde, é analisar os sentidos atribuídos discursivamente à febre amarela silvestre durante a cobertura jornalística da epizootia da doença, ocorrida no Brasil no verão 2007-2008. Utilizando o referencial teórico das práticas discursivas e da produção de sentidos no cotidiano e as hipóteses de agendamento (agenda-setting) e enquadramento (framing) da notícia, foram analisadas todas as matérias sobre febre amarela veiculadas pelo jornal Folha de S. Paulo, no período de 21 de dezembro de 2007 a 29 de fevereiro de 2008, e todos os documentos oficiais sobre a epizootia emitidos pela autoridade brasileira de saúde pública entre 3 de janeiro e 28 de fevereiro de 2008. Os achados indicam que as estratégias discursivas da cobertura jornalística relativizaram o discurso da autoridade de saúde pública; priorizaram a divulgação do número de casos; enfatizaram a vacinação como o limite entre a vida e a morte, omitindo riscos do uso indiscriminado do imunobiológico; e propagaram a iminência de uma epidemia de febre amarela de grandes proporções. Essas estratégias deram novos sentidos à doença, deslocando o evento de sua forma silvestre, espacialmente restrita e de gravidade limitada, para a urbana, de caráter epidêmico e potencialmente mais grave. Secundariamente, o estudo permitiu identificar os impactos desse discurso midiático sobre o sistema nacional de imunização e os riscos a que a população foi exposta em função dos sentidos produzidos: em 2008, foram registrados 8 casos de reação grave à vacina, dos quais 6 foram a óbito.

\author{
${ }^{1}$ Mestre e doutoranda em \\ Saúde Pública pela Faculdade \\ de Saúde Pública da USP. \\ Endereço eletrônico: claudia. \\ malinverni@usp.br \\ 2 Faculdade de Saúde Pública \\ da Universidade de São \\ Paulo. Endereço eletrônico: \\ abcuenca@usp.br \\ ${ }^{3}$ Professora doutora do Curso \\ de Obstetrícia da Escola de \\ Artes, Ciências e Humanidades \\ da Universidade de São \\ Paulo. Endereço eletrônico: \\ jbrigagao@yahoo.com
}

> Palabras clave: febre amarela; jornalismo; comunicação em saúde; práticas discursivas; agenda-setting; framing. 


\section{Introdução ${ }^{1}$}

Um dos maiores fenômenos sociais do Ocidente, a comunicação midiática, notadamente em sua vertente de massa, tem desempenhado papel central nos processos de construção da realidade nas sociedades contemporâneas. No campo da comunicação, o jornalismo emerge como área estratégica para a configuração mediada do espaço público, representando uma cultura de forte intervenção no cotidiano das populações, e ancorada em uma relação social "densa e demarcada, um modo específico de buscar e narrar a informação, um tipo de saber, uma práxis que inclui a construção da personalidade pública do jornalista e um ethos jornalístico" (KUCINSKI, 2000, p. 182).

A mídia configura-se, assim, como poderosa prática discursiva capaz de produzir sentidos, por sua vez entendidos como uma construção social, de caráter coletivo e interativo, em que as pessoas, na dinâmica de suas relaçôes sociais, historicamente datadas e culturalmente localizadas, constroem os termos que lhes permitem compreender e lidar com as situações e fenômenos no cotidiano (SPINK; MEDRADO, 2004).

Pela hipótese do agendamento midiático (agenda-setting) do acontecimento cotidiano, as pessoas sabem ou ignoram, prestam atenção ou descuram, realçam ou negligenciam elementos específicos do cenário público. Dito de outra forma, a mídia tem o poder de dizer sobre o que as pessoas devem falar, sendo a realidade social dada, em grande parte, por empréstimo, em "fatias/pacotes" de realidade que as pessoas acessam exclusivamente por meio da mediação simbólica (WOLF, 1999; SHAW, 1979). Ao agenda-setting soma-se a hipótese do framing (enquadramento), o qual, de acordo com Entman (1993), confere à mídia também o poder de definir não apenas o quê, mas como as pessoas devem pensar os temas do cotidiano. Enquadrando o acontecimento a partir de uma "moldura", a mídia direciona o leitor/ouvinte/telespectador para uma realidade parcial (MARECO; PASSETTI, 2010).

Ancorado nesses referenciais, o presente trabalho buscou demonstrar como o jornalismo generalista, por meio da análise da cobertura do jornal Folha de S.Paulo, deslocou discursivamente o sentido de uma doença, neste caso a epizootia de febre amarela, no verão 2007-2008, de sua forma silvestre, espacialmente restrita e de gravidade limitada, para a forma urbana, de caráter epidêmico e potencialmente mais grave. 


\section{Modelo de vigilância e a midiatização da febre amarela}

A febre amarela é uma doença infecciosa febril aguda, não contagiosa, de curta duração e gravidade variável, causada por arbovírus do gênero Flavivirus, da família Flaviviridae. De caráter endêmico ou enzoótico (BRASIL, 2005), foi descrita pela primeira vez em 1648, em Yacatán, México, expandindo-se rápida e progressivamente para as Américas Central e do Sul, atingindo também algumas áreas portuárias ao norte do continente americano (LÖWY, 2006). Ainda hoje importante causa de morbidade e letalidade em extensas áreas tropicais das Américas e da África, origem do vírus, a febre amarela afeta anualmente cerca de 200 mil pessoas, provocando 30 mil óbitos (BRASIL, 2008; VASCONCELOS, 2003), sendo, assim, um problema de saúde pública de nível global.

No Brasil, durante décadas, as áreas urbanas foram o principal cenário das epidemias amarílicas, que ocorriam ciclicamente e tinham, em geral, grandes proporções. Esses eventos eram provocados pelo mosquito Aedes aegypti, identificado pelo saber cientifico da época como o único vetor da febre amarela urbana (VASCONCELOS, 2003). Essa crença orientou toda a política pública mundial de combate à doença, particularmente no Brasil, que por mais de meio século centrou sua ação na erradicação do Aedes, da qual a campanha de Oswaldo Cruz, no começo do século XX, é emblemática (VASCONCELOS, 2003; LÖWY, 2006).

Ancorada fortemente no ideário dos pesquisadores norte-americanos da Fundação Rockfeller, a perspectiva da erradicação manteve-se no centro das políticas públicas brasileiras de controle da doença por mais de 20 anos, mesmo depois da descoberta, em 1932, de que a doença é dividida em dois ciclos: um urbano e outro silvestre. Eles diferem, respectivamente, quanto ao agente envolvido na transmissão (mosquitos hematófagos da família Culicidae), hospedeiro amplificador (humanos e símios) e área de ocorrência (cidades e florestas). Embora, dos pontos de vista etiológico, clínico, imunológico e fisiopatológico, trate-se da mesma doença, em ambiente urbano do continente americano, a febre amarela é transmitida exclusivamente pela fêmea infectada do Aedes aegypti, enquanto no silvestre, outras espécies estão envolvidas, principalmente o Haemagogus e o Sabethes (VASCONCELOS, 2003; GOMES et al., 2010; BRASIL, 1999). No que diz respeito ao hospedeiro, a transmissão da febre amarela urbana é feita do A. aegypti para o homem, responsável, portanto, pela amplificação e disseminação 
do vírus. No ambiente silvestre, os primatas não humanos arborícolas são os hospedeiros primários, sendo os seres humanos não imunizados infectados acidentalmente, quando entram em áreas de circulação do vírus (TAUIL, 2010).

Embora a descoberta do ciclo silvestre tenha evidenciado a impossibilidade de erradicação da doença, a insistência em combater o $A$. aegypti rendeu ao Brasil a eliminação da forma urbana da febre amarela. Em 1942, o país registrou os três últimos casos de febre amarela urbana em Sena Madureira, no Acre, sendo o território brasileiro declarado livre do A. aegypti em 1958 pela Organização PanAmericana da Saúde (OPAS) (TAUIL, 2010). O mosquito reinfestaria o Brasil a partir de 1976, como vetor do dengue (VASCONCELOS, 2003; GOMES et al., 2010; BRASIL, 1999; TAUIL, 2010).

A febre amarela silvestre ocorre ciclicamente em três áreas de circulação do vírus, de acordo com classificação do Ministério da Saúde: endêmica, epizoótica ou de transição (o território é livre da doença na área indene). Desde 1997, em razão da mudança de perfil da ocupação territorial (principalmente pelo avanço da agropecuária, da domiciliação de áreas de mata e florestas e pela intensificação do ecoturismo), as áreas de circulação viral vêm sofrendo forte tendência de ampliação (BRASIL, 2004).

Apresentando epizootias regulares a cada 5 ou 7 anos, prevalentemente nos meses de chuva, o ciclo silvestre é monitorado por um sistema público de vigilância que tem como evento sentinela o adoecimento e/ou a morte de macacos. A confirmação desses óbitos é um forte indicativo de que o vírus amarílico está circulando entre a população símia e, consequentemente, de que uma epizootia de febre amarela está em curso, o que representa elevado risco de transmissão da doença a seres humanos não imunizados que entram nessas áreas (BRASIL, s.d.).

Doença de notificação compulsória internacional, submetida ao Regulamento Sanitário Internacional da Organização Mundial da Saúde (RSS/OMS), qualquer evidência de atividade viral, inclusive em áreas indenes, deve ser imediatamente notificada aos diferentes níveis hierárquicos do Sistema Único de Saúde (SUS) (BRASIL, 1999). A identificação precoce da circulação viral desencadeia uma série de ações, como a vacinação de viajantes e da população residente nas áreas de transmissão, que têm por objetivo evitar a ocorrência de casos humanos e o ressurgimento da forma urbana (BRASIL, 2005; 2008; s.d; GOMES, 2010; TAUIL, 2010). 
Adotado pelo Ministério da Saúde em 2003, esse modelo de vigilância

está na base do processo que pôs o surto de febre amarela silvestre, no verão 2007-2008, no centro de interesse da imprensa, desencadeando o processo de midiatização ${ }^{2}$ do acontecimento amarílico. O primeiro caso humano, divulgado em uma nota técnica da Secretaria de Saúde do Distrito Federal e repercutido no Correio Braziliense, principal jornal da capital federal, desencadeou o processo de agendamento da notícia (MACHADO, 2008). Embora, desde o início, o evento tivesse sido classificado pela maioria dos especialistas e por todas as autoridades de saúde pública como dentro da normalidade, de modo geral, a cobertura jornalística enquadrou a febre amarela silvestre sob a perspectiva de uma epidemia fora do controle.

\section{Metodologia}

A Folha de S.Paulo foi escolhida em razão de seu reconhecido papel como jornal formador de opinião em âmbito nacional, muitas vezes servindo como fonte de informação para diferentes mídias (rádio, televisão, internet e jornais regionais). Para dar apoio à pesquisa, foram identificados e analisados documentos oficiais divulgados pela Secretaria de Vigilância em Saúde do Ministério da Saúde (SVS/ MS) ao longo do surto de febre amarela silvestre.

As matérias jornalísticas foram entendidas como documentos de domínio público. Como afirma Spink (2000, p. 136), esses documentos estão eticamente abertos a análise exatamente por terem sido tornados públicos de uma forma que permite sua responsabilização, podendo "refletir as transformações lentas em posições e posturas institucionais assumidas pelos aparelhos simbólicos que permeiam o dia a dia ou, no âmbito das redes sociais, pelos agrupamentos coletivos que dão forma ao informal, refletindo o ir e vir de versões circulantes assumidas ou advogadas".

Para analisar as versões circulantes na cobertura jornalística do jornal, a estratégia metodológica utilizada foi a da análise do discurso, pautada na perspectiva de que a linguagem permite construir múltiplas versões de um evento. Nesse processo, os repertórios interpretativos desempenham papel fundamental, sendo, conforme Potter e Wetherell (1987), um conjunto de termos, descrições e figuras de linguagem socialmente compartilhados e utilizados nas produções discursivas como base para a argumentação. 


\section{Corpus jornalístico}

As matérias analisadas no presente estudo foram publicadas na Edição SP do jornal Folha de S.Paulo. ${ }^{3} \mathrm{O}$ acesso ao noticiário que formou o corpus jornalístico deu-se exclusivamente por meio eletrônico, cujo conteúdo é restrito a assinantes do jornal ou do portal UOL. O período analisado foi de 21 de dezembro de 2007 a 29 de fevereiro de 2008, recorte temporal que compreende a publicação da primeira e da última matéria circunscrita ao fenômeno midiático da febre amarela. Para localização das matérias foi utilizado o termo "febre amarela 2008”, em campo de busca próprio do arquivo eletrônico do jornal, disponível no portal UOL. Todas as matérias localizadas sob esse termo foram arquivadas em Word, seguindo-se posteriormente à leitura de cada texto.

O termo "febre amarela" foi localizado em 120 matérias, publicadas em 48 edições e distribuídas por dez editorias: "Capa", "Opinião", "Brasil”, "Ciência”, "Dinheiro", "Cotidiano", "Esporte", "Ilustrada”, "Turismo" e "Ombudsman”. Desse total, dois registros (e uma editoria, a de turismo) foram descartados em razão de o termo não estar relacionado à cobertura jornalística do episódio ora analisado. Foram efetivamente analisadas 118 matérias, veiculadas em 47 edições e nove editorias.

As matérias do corpus jornalístico foram organizadas por data, título, editoria, autoria e endereço eletrônico de acesso. Os textos foram categorizados em nove gêneros/estilos, de acordo com a prática jornalística: reportagem, texto de opinião, nota em coluna de opinião, notícia, chamada de capa, destaque de página, entrevista, carta de leitor e editorial.

\section{Corpus institucional}

Foi feito um levantamento dos documentos oficiais relativos ao surto de febre amarela silvestre, emitidos pela SVS/MS, que serviram de apoio à análise qualitativa do corpus jornalístico. Foram localizados e analisados 40 documentos, entre 3 de janeiro e 28 de fevereiro de 2008, período em que a autoridade de saúde pública manteve comunicações frequentes sobre a situação da epizootia. Os documentos foram divididos em seis categorias, segundo nomenclatura adotada pelo Ministério da Saúde: notícia no portal, aviso de pauta, nota, comunicado, glossário e boletim. 
A análise do corpus jornalístico foi realizada em duas etapas. Na primeira, um estudo exploratório evidenciou a visibilidade dada ao tema na cobertura do jornal. $\mathrm{Na}$ segunda etapa, utilizando os referenciais teóricos citados, evidenciaram-se os processos de agendamento e enquadramento da notícia, bem como a produção de sentidos, por meio de estudo dos repertórios interpretativos que circularam no noticiário. Esses repertórios foram separados em quatro categorias: nomeação, descrição epidemiológica, caracterização da doença e discurso oficial. Cada uma das categorias foi analisada, primeiro, individualmente. Em seguida, buscaramse os sentidos que o conjunto das quatro categorias produziu sobre a febre amarela transformada em notícia.

A referência à doença sem a indicação (nomeação) de que se tratava do ciclo silvestre tornou, discursivamente, as duas formas (silvestre e urbana) um mesmo e único evento. A estratégia discursiva baseada na descrição epidemiológica (termos e descrições como "áreas de risco", "surto", "epidemia", "notificação de casos", etc.) produziu o sentido de expansão territorial do evento. A caracterização da doença (sintomatologia e tratamento) deslocou o sentido da febre amarela da perspectiva coletiva para a individual: ao reconhecerem sinais e sintomas de uma doença, é possível que os leitores do jornal tenham considerado a chance real de adoecerem. Finalmente, ao relativizar as ações e políticas públicas para o controle e prevenção da doença (o discurso oficial), a cobertura jornalística evidenciou a iminência de uma epidemia fora do controle governamental.

Na primeira etapa da análise foram identificadas as editorias e os estilos/gêneros jornalísticos (conforme o gráfico 1) em que foram veiculadas as 118 matérias que compõem o corpus jornalístico. Chama a atenção o número expressivo de textos e notas em coluna de opinião, carta de leitor e editorial (37,3\% da cobertura), que são essencialmente de natureza interpretativa e, geralmente, não trazem informação nova, sendo antes a manifestação de um juízo de valor sobre fatos e acontecimentos do que a exposição da verdade factual (BAHIA, 1990; SOUSA, 2006). Já as notícias, de caráter essencialmente objetivo (BAHIA, 1990), responderam por apenas $13,5 \%$ da cobertura, enquanto o gênero reportagem, situado entre a objetividade e a subjetividade (BAHIA, 1990), respondeu por $25,7 \%$. A preponderância das matérias de natureza não jornalística implica dizer que a cobertura teve um alto grau de subjetivação (SOUSA, 2006). 


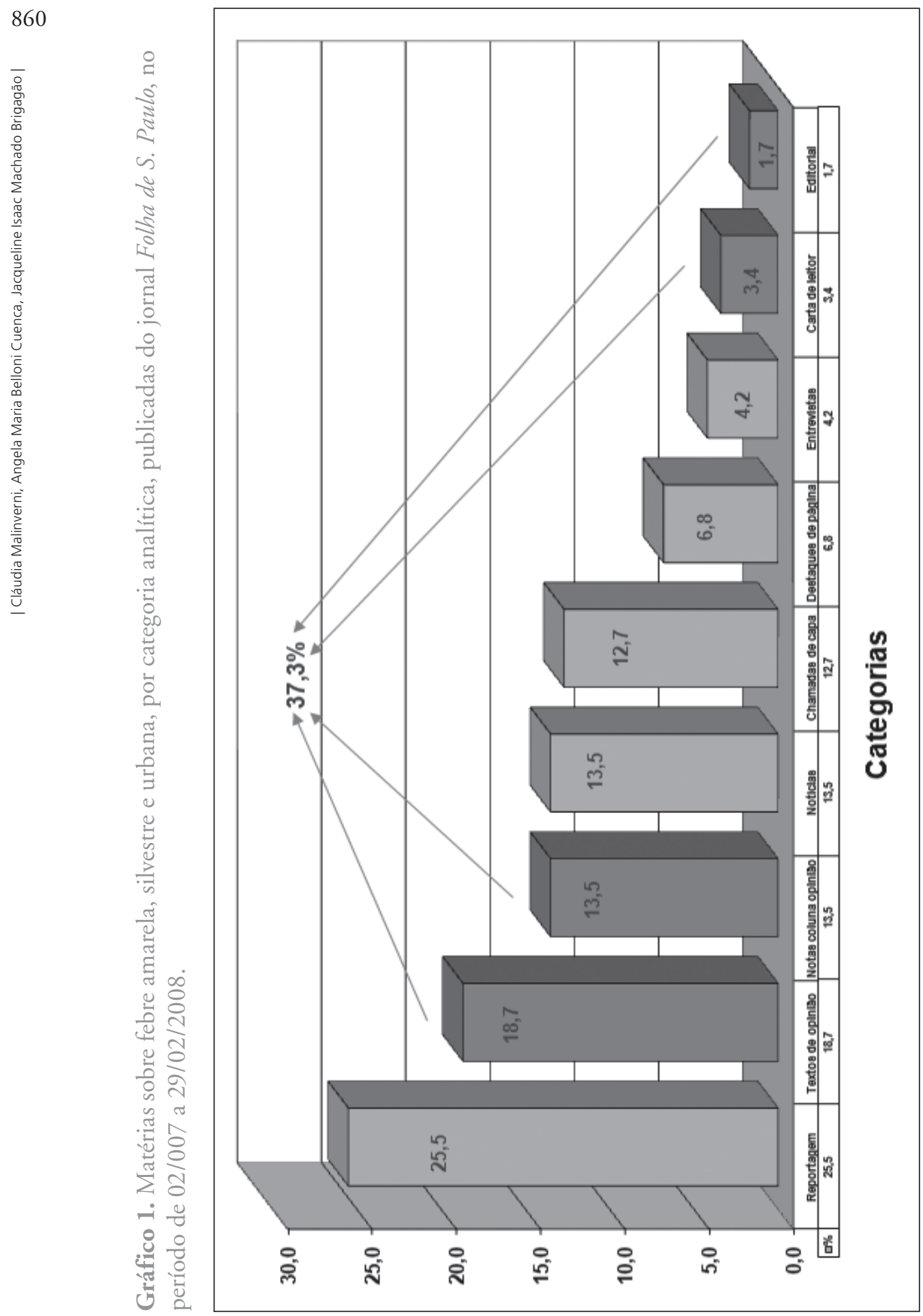


Em seguida, realizou-se uma análise das principais estratégias discursivas sobre a febre amarela apresentadas ao longo da cobertura, identificando os modos como a doença foi apresentada, quais sejam: a não discriminação dos dois ciclos epidemiológicos; negatividade, dramaticidade e inevitabilidade; enquadramento epidêmico; e foco na vacina como limite entre a vida e a morte.

\section{Discussão}

\section{Qual febre amarela?}

$\mathrm{Na}$ maior parte da cobertura jornalística, a diferença entre as duas formas da doença (silvestre e urbana) não foi explicitada. O primeiro registro localizado ("Morte de macacos por febre amarela intensifica vacinação", Folha de S.Paulo, 21/12/07), texto do gênero notícia, embora faça referência à ocorrência de uma epizootia, não é explícito quanto ao ciclo que estava em curso, o silvestre. Ao contrário, há referência à forma urbana. O segundo registro ("Parque fechado por febre amarela reabre", Folha de S.Paulo, 02/01/2008) traz um grave erro de informação ao indicar o Aedes aegypti como o vetor envolvido na epizootia. Nas Américas, incluindo o Brasil, os transmissores da febre amarela silvestre são basicamente os mosquitos Haemagogus e Sabethes, sendo o A. aegypti responsável exclusivamente pela transmissão da forma urbana (VASCONCELOS, 2003).

Dois pequenos registros foram localizados nos dias 3 e 5 de janeiro de 2008. No dia seguinte, o jornal publicou notícia sobre a ocorrência do primeiro óbito humano possivelmente provocado pela doença. Embora conciso, o texto ("Morre paciente com suspeita de febre amarela", Folha de S.Paulo, 06/01/08) apresenta alto grau de noticiabilidade, ${ }^{5}$ sendo identificado neste estudo como aquele que desencadeou o processo de agendamento da doença na Folha.

É importante observar, ainda, que, apesar de os registros se referirem à forma silvestre, em nenhum deles o ciclo é nomeado. Essa nomeação é essencial para identificação epidemiológica do agravo em curso. Ressaltamos que àquela altura, a informação de que se tratava da forma silvestre já havia sido destacada no documento "Vacinação contra febre amarela previne doença no DF" (03/01/2008), amplamente divulgado pela área de comunicação da SVS/MS.

Como já referido, a ausência da nomeação "silvestre" não caracteriza o evento como uma ocorrência geograficamente localizada e de gravidade limitada. À omissão dessa informação soma-se a ênfase dos textos no ciclo urbano, formando 
um pacote interpretativo segundo o qual o leitor da área urbana, público alvo da edição analisada, poderia ser levado a sentir-se diante de um evento prestes a eclodir na porta de sua casa.

\section{Negatividade, dramaticidade, inevitabilidade}

$\mathrm{O}$ primeiro óbito suspeito levou o jornal a ampliar consideravelmente o espaço dedicado à febre amarela, enfatizando nos textos o crescimento de casos suspeitos e as consequências da doença, o que amplificou, discursivamente, a negatividade e a inevitabilidade de uma possível epidemia. Publicada em 8 de janeiro de 2008, a primeira reportagem ("Mais uma pessoa morre com suspeita de febre amarela") destacou o número "crescente" de casos suspeitos na região CentroOeste, enfatizando sintomas e tratamento dos internados em estado grave. Pela primeira vez, há referência às formas urbana e silvestre; contudo, ao colocar o foco no crescimento de casos e na sintomatologia/tratamento, o texto pode ter induzido o leitor a acreditar que a febre amarela estava se alastrando pelo Brasil.

Em 9 de janeiro, a doença chegou à primeira página da Folha ("Suspeita de febre amarela provoca corrida a postos no DF), ganhando assim status de tema importante e "quente" no horizonte de atualidade jornalística projetado pelo jornal (SOUSA, 2006). Ao longo do período estudado, o tema recebeu 15 capas $(12,7 \%$ do total da cobertura), das quais 12 foram publicadas quase consecutivamente entre os dias 9 e 21 de janeiro (o tema só não ocupou a primeira página em 18 de janeiro). Sendo a capa um dos mais nobres espaços da mídia impressa, em razão do limitado número de assuntos nela destacados (BAHIA, 1990), esse total demonstra a relevância editorial dada ao tema.

Trechos das chamadas de capa dos dias 11, 15, 16, 17 e 20 de janeiro "primeira morte", "2 2 a morte", " 5 a morte", "7 mortes", "8 o total de mortes", "9a morte", respectivamente - evidenciam também que os óbitos foram enquadrados na forma de escalada. Fica implícita nessa sequencia de chamadas de capa a ideia de "descontrole" da epidemia, já que o número de casos fatais "crescia” em progressão aritmética, num curto período de tempo. Essa estratégia discursiva produziu sentidos que salientaram a negatividade, a dramaticidade e a inevitabilidade do acontecimento, enquadramento que conferiu ao registro jornalístico uma natureza mais emotiva do que informativa (SOUSA, 2006). 


\section{Enquadramento epidêmico}

Das 118 matérias analisadas, 75 (42\%) foram publicadas entre 9 e 22 de janeiro (12 ediçôes consecutivas), caracterizando o período como o ápice do agendamento noticioso da febre amarela na Folha e do enquadramento epidêmico. A edição emblemática desse enquadre é a de 14 de janeiro, quando o tema foi manchete (destaque principal da primeira página) e reportagem central da editoria "Cotidiano" (com seis textos e um destaque de página).

Nesse registro, chama a atenção o primeiro texto da reportagem. O título "Ministro vai à TV negar epidemia de febre amarela" alinha-se ao texto de abertura, que diz: "No dia em que o número de notificaçôes de casos suspeitos de febre amarela subiu de 15 para 24, o ministro José Gomes Temporão (Saúde) foi à TV fazer um pronunciamento em cadeia nacional para dizer que 'não existe risco de epidemia'". Nessa leitura, a ênfase no aumento nas notificações de casos suspeitos relativiza (para baixo) o valor absoluto da informação dada pela autoridade de saúde pública, qual seja, de que o país não corria risco de sofrer uma epidemia de febre amarela. Essa relativização pode ter produzido no leitor leigo a ideia de que o ministro, logo, o próprio governo federal, recusava-se a aceitar um acontecimento que, discursivamente, parecia consumado: os números estavam configurando a febre amarela como um evento epidêmico.

Também se destacam nessa reportagem dois textos do gênero entrevista. No primeiro, um especialista renomado apresenta uma defesa veemente da vacinação antiamarílica obrigatória. Direcionado pela reportagem, que pergunta se ele acreditava na possibilidade de uma epidemia urbana da doença, o especialista confirma os riscos reais de ocorrência dessa forma da doença. Finalmente, o discurso do entrevistado extrapola as proposições científicas e se finca em um postulado moral, segundo o qual, na falta de assertividade do poder público para evitar a "tragédia" iminente, o Brasil dependeria de deliberações divinas: "Rezemos para que isso [a febre amarela urbana] não aconteça" ("Infectologista defende vacina obrigatória", Folha de S.Paulo, 14/01/08).

O segundo entrevistado, contrário à tese da epidemia, responsabiliza a mídia pela criação do sentido epidêmico da doença: "O que acontece é um fenômeno de imprensa. E isso é clássico na história das epidemias. Toda vez que surge uma, os governos negam. E a imprensa vai atrás, no rastro da doença” (“É uma 
situação normal, diz Dráuzio Varella”, Folha de S.Paulo, 14/01/08). Entre as duas entrevistas são apresentados os argumentos dos especialistas que refutam a hipótese de reurbanização da febre amarela e descartam a vacinação em massa, em texto de apenas 135 palavras.

O descuramento (omissão) do discurso oficial é evidenciado na entrevista publicada em 15 de janeiro, na qual uma especialista em Saúde Pública da Universidade de Harvard (EUA) lista uma série de recomendaçoes às autoridades brasileiras para o enfrentamento da febre amarela. Ressalte-se que estas já haviam sido publicizadas pela autoridade de saúde em dois documentos oficiais ("Material de apoio para jornalistas" e "Temporão descarta epidemia de febre amarela"), divulgados pelo Ministério da Saúde em 9 de janeiro, seis dias antes, portanto, da publicação da entrevista. Ambos os documentos descrevem as principais medidas do sistema nacional de vigilância da febre amarela, entre elas a vacinação da população que vive ou viaja para áreas de risco, medida destacada pela norteamericana. Não há no jornal qualquer referência aos documentos oficiais.

\section{Revolta pela vacina, afogando em números}

A ênfase na vacinação contra a febre amarela é explicitada na reportagem de 17 de janeiro, cujo texto emblemático tem por título "Com filas nos postos de saúde, Rio vive agora 'revolta pela vacina'”. Trata-se de uma referência à centenária "Revolta da vacina", levante popular ocorrido no Rio de Janeiro, no começo do século XX, contra a obrigatoriedade da vacinação da varíola, com amplo apoio da imprensa. Na estratégia discursiva, destaca-se a troca da preposição "da" por "pela", que traz, quase um século depois, a mesma voz jornalística que prega contra a "ineficiência" do poder público brasileiro em controlar epidemias.

A ênfase no aumento progressivo do número de casos humanos suspeitos de febre amarela, com destaque para os óbitos, representou outro importante mecanismo para a configuração simbólica da febre amarela silvestre como uma realidade epidêmica inevitável. No principal texto da reportagem ("Mortes por febre amarela já superam 2007”, 17/01/08), o jornal destaca o curto período em que a doença progrediu, 16 dias. O texto compara os casos de 2008 com os de 2007, 2006, 2004 e 2003, omitindo 2001 e 2002, anos inseridos no ciclo regular da epizootia, e que apresentaram números expressivamente maiores do 
que no mesmo período de 2008. Além da escolha editorial dos dados a serem

apresentados ao leitor, a matéria omite o perfil cíclico da febre amarela silvestre, que apresenta epizootias regulares a cada 5 ou 7 anos (BRASIL, 2005; 2008; GOMES et al., 2010).

Um texto do ombudsman do jornal faz uma dura crítica à cobertura jornalística da febre amarela em geral e à da Folha em particular, sobretudo no que diz respeito ao uso dos números:

O exagero da Folha em 2008 contrasta com outro, o de 2001, quando os 22 óbitos se concentraram no primeiro trimestre. Em nenhum dia daquele ano a primeira página se referiu à moléstia [...] nota [de rodapé] anunciara semanas antes as 39 mortes do ano anterior [2000] [...] registros não trouxeram a opinião do então ministro da Saúde [...]. Em 2000, nenhum título da capa falou em morte pela doença ("Jornalismo febril”, Folha de S.Paulo, 27/01/08).

Esses números também expressaram o confronto entre a instância discursiva oficial (epidemiologia e poder público) e a instância discursiva midiática, cada uma das quais tentando legitimar e impor a sua perspectiva. Nessa disputa, o enquadre jornalístico deu aos números uma espécie de "autonomia” de sentidos ("os números falam por si”), que desqualificava o discurso oficial, então centrado no argumento epidemiológico que definia o episódio como "dentro da normalidade".

É importante observar, ainda, que a estratégia discursiva calcada na progressão numérica não apenas estabelece a importância do fenômeno em si, como dá a ele um caráter de irreversibilidade (HERZLICH; PIERRET, 2005). Assim, a divulgação sistemática do número de casos suspeitos contribuiu significativamente para a configuração simbólica da febre amarela silvestre de 2007-2008 como uma realidade urbana e epidêmica.

Também chama atenção a politização do tema, que, a partir de 10 de janeiro de 2008, passou a ser destacado em várias edições seguidas nas editorias "Opinião" e "Brasil", espaços de excelência dos temas de interesse nacional, como política e economia. Entre 10 e 21 de janeiro, ápice do agendamento da febre amarela na Folha, 23 das 75 matérias foram publicadas nessas duas editorias, em textos essencialmente interpretativos (editorial, textos e notas de opinião). Ressaltamos que apenas no dia 20 o jornal publicou o primeiro, e único, texto de opinião assinado por um especialista em saúde, sob o título "Nem todos precisam de vacina", na editoria "Cotidiano". 
A análise do movimento do noticiário indica que a partir de 21 de janeiro a agenda febre amarela começou a se esgotar na Folha, com deslocamento progressivo dos textos do gênero reportagem para o gênero notícia. Entretanto, o primeiro óbito suspeito de febre amarela vacinal deu novo impulso à noticiabilidade do acontecimento, recolocando o tema na agenda: a doença voltou a ser capa nos dias $1^{\circ}$ e 2 de fevereiro. Àquela altura, o Brasil registrava 43 casos de reaçôes adversas à vacina amarílica, mais do que o dobro do total de casos da doença provocados pelo mosquito confirmados em humanos - 19 casos entre dezembro de 2007 e 31 de janeiro de 2008 (BRASIL, 2008).

Em seguida, a Folha de S.Paulo passou a dedicar espaços cada vez menores à febre amarela. Nos dias 13, 16, 19, 23 e 29 de fevereiro, na editoria "Cotidiano", foram veiculados os últimos textos sobre a doença, todos no gênero notícia. Ao longo dos meses seguintes, o jornal restringiu-se à atualização de dados oficiais, sem voltar a dar ao tema o mesmo grau de noticiabilidade observado no período de estudo.

\section{Vacinação, repertório recorrente}

A vacinação contra a febre amarela foi um repertório recorrente em praticamente toda a mídia generalista, da qual, neste estudo, o jornal Folha de S.Paulo é representativo. Essa perspectiva midiática causou forte impacto sobre o Programa Nacional de Imunizações do Ministério da Saúde. Entre o final de dezembro de 2007, quando as primeiras notícias sobre a doença começaram a ser veiculadas nacionalmente por diversos veículos de imprensa de todo o país, e 22 de fevereiro de 2008, quando teve início o processo de esgotamento noticioso da febre amarela, foram distribuídas aos estados e ao Distrito Federal 13.630.700 doses da vacina antiamarílica (BRASIL, 2008). Trata-se de um número exponencial, considerando a série histórica do programa, que rotineiramente distribui entre 15 e 16 milhões de doses ao longo de um ano, ou, aproximadamente, 1,35 milhão de doses ao mês (BRASIL, 2008). Em pouco menos de dois meses, mais de 7,6 milhões de vacinas foram aplicadas - 6,8 milhões só em janeiro, mês em que foi registrado o maior volume de notícias sobre a doença (BRASIL, 2008). A grande maioria das pessoas não tinha indicação para a vacina (BRASIL, 2008; 2009).

No início de fevereiro de 2008, em razão do aumento exponencial da demanda interna, o Brasil - um dos três fabricantes mundiais pré-qualificados pela 
Organização Mundial da Saúde para a produção da vacina amarílica - suspendeu a exportação do imunobiológico (Brasil, 2008; WHO, 2008). Antes, em 18 de janeiro de 2001, o Ministério da Saúde já havia apresentado à OMS um pedido de empréstimo de 4 milhões de doses do estoque de emergência global, para manter em níveis seguros o estoque nacional do antiamarílico e, ao mesmo tempo, assegurar uma eventual campanha de vacinação de emergência (WHO, 2008).

Fabricada desde 1937, no Brasil, pelo Bio-Manguinhos, a vacina contra a febre amarela tem demonstrado segurança e efetividade no controle da doença, com raros registros de complicações graves pós-vacinais - a literatura refere que de $2 \%$ a $5 \%$ dos vacinados apresentarão algum tipo de reação ${ }^{6}$. Porém, como qualquer produto farmacêutico, também ela pode apresentar efeitos colaterais ou eventos adversos, algumas vezes bastante graves, como é o caso da doença viscerotrópica (DV). Forma mais rara e grave do vírus vacinal, a DV pode causar choque, derrame pleural e abdominal e falência múltipla dos órgãos (BRASIL, 2005; 2009).

Ao longo das últimas décadas, eventos viscerotrópicos têm sido bastante raros no país. Em nove anos (1999-2007), o Sistema de Vigilância de Eventos Adversos Pós-Vacinação (EAPV), vinculado ao Programa Nacional de Imunização do Ministério da Saúde (PNI/MS), registrou 8 casos, com 7 óbitos. Contudo, em 2008, foram confirmados 8 casos de reação adversa grave à vacina amarílica, dos quais seis foram a óbito. Dessas mortes, duas foram confirmadas como DV e uma, até o encerramento da presente pesquisa, ainda estava em investigação (BRASIL, 2009).

A ênfase na proteção permanente conferida pela vacina contra a febre amarela acabou por alçá-la, simbolicamente, à categoria de "poção mágica". O foco midiático na vacinação como a única estratégia capaz de impedir a ocorrência da doença foi responsável pela busca indiscriminada da população pelo imunobiológico.

\section{Considerações finais}

A análise dos repertórios interpretativos que circularam na cobertura da Folha de S.Paulo nos permitiu entender os sentidos produzidos sobre a febre amarela e como, discursivamente, a cobertura jornalística fez existir uma realidade epidêmica. Sob a perspectiva do agenda-setting foi possível constatar que, a partir 
do momento em que o acontecimento amarílico ganhou relevância editorial, a produção desse sentido se deu em razão da forte presença de dois conceitos: acumulação, uma vez que o assunto foi abordado continuamente em seguidas ediçôes e por um longo período de tempo; e onipresença, sendo o tema exposto em diversas editorias. $\mathrm{O}$ direcionamento editorial crivou o acontecimento de subjetividade, como demonstra a análise quantitativa dos gêneros jornalísticos veiculados ao longo da cobertura, na qual há preponderância de textos de natureza interpretativa sobre os de natureza objetiva. Nessa construção, a Folha de S.Paulo, ao mesmo tempo, impôs a febre amarela à agenda cotidiana dos seus leitores e determinou a forma pela qual a doença deveria ser interpretada, enquadrando (framing) o tema como um evento potencialmente epidêmico, perigoso e letal.

Apoiando-se fortemente em fontes contrárias às postulaçôes de normalidade do evento, as matérias produzidas pelo jornal deram intensa visibilidade (saliência) às informaçôes que visavam relativizar a instância discursiva oficial. Esta, por sua vez, embora tenha realizado, ao longo de todo o período estudado, esforços permanentes de comunicação, a fim de minimizar os efeitos dos sentidos que deslocavam a doença para uma forma epidêmica, não conseguiu impor-se ao fluxo discursivo midiático. O motivo dessa ineficácia comunicativa por parte do poder público não foi objeto da presente pesquisa, mas pode ser norteador de futuros estudos, de modo a contribuir para o equilíbrio da complexa e conflituosa relação entre a mídia privada e os gestores da saúde pública.

As repercussões que os sentidos midiatizados da febre amarela tiveram sobre os processos saúde/enfermidade vivenciados pelas pessoas no cotidiano e seus impactos sobre o sistema público de saúde demandam uma discussão crítica sobre o papel do jornalismo generalista no campo da saúde. Todas as práticas discursivas implicam um fazer cotidiano, inclusive do jornalismo. A bandeira da liberdade de expressão, reconhecida e legitimada nas sociedades ocidentais como instrumento fundamental à cidadania, não pode servir de salvo conduto ao fazer jornalístico. Ao contrário, como produtor poderoso de significação e construtor da realidade social, ele também deve ter em perspectiva as complexidades dos processos do adoecimento humano e os limites do conhecimento no tratamento das doenças ${ }^{6}$. 


\section{Referências}

BAHIA, J. Jornal, história e técnica: história da imprensa brasileira. São Paulo: Ática; 1990. BRASIL. Ministério da Saúde. Fundação Nacional de Saúde. Manual de vigilância epidemiológica de febre amarela. Brasília, DF, 1999. Disponível em: http://portal.saude.gov. br/portal/arquivos/pdf/manu_feam.pdf. Acesso em: 9 out. 2008.

BRASIL. Ministério da Saúde. Secretaria de Vigilância em Saúde. Açôes transversais da vigilância em saúde: promoção, integração, e análise: gestão 2007-2008. Brasília, DF, 2009, p. 184-9.

BRASIL. Ministério da Saúde. Secretaria de Vigilância em Saúde. Manual de vigilância de epizootias em primatas não humanos. Brasília, DF, 2005.

BRASIL. Ministério da Saúde. Secretaria de Vigilância em Saúde. Programa Nacional de Vigilancia da Febre Amarela. Brasília, DF, 2008. Disponível em: http://portal.saude.gov.br/ portal/arquivos/pdf/Febre\%20Amarela-site-SVS-31out2008.pdf. Acesso em: 27 jan. 2010. BRASIL. Ministério da Saúde. Secretaria de Vigilância em Saúde. Recomendação de vacinação contra febre amarela para viajantes com destino ao Brasil [documento na internet]. Brasília, DF [s./d.]. Disponível em: http://www.conbrasil.org.ar/CONSBRASIL/files/ febre_amarela.pdf. Acesso em: 13 nov. 2010.

BRASIL. Ministério da Saúde. Secretaria de Vigilância em Saúde. Situação da prevenção e controle das doenças transmissiveis no Brasil. Brasília, DF, 2004.

ENTMAN R. M. Framing: toward clarification of a fractured paradigm. Journal of Communication, Washington, DC , v. 43, n. 4, p. 51-58, 1993.

GOMES A. C. et al. Ecologia de Haemagogus e Sabethes (Díptera: Culicidae) em áreas epizoóticas do vírus da febre amarela, no Rio Grande do Sul, Brasil. Epidemiol. Serv. Saúde, Brasília, DF, v. 19, n. 2, p. 101:113, jun. 2010.

HERZLICH, C.; PIERRET, J. Uma doença no espaço público: a AIDS em seis jornais franceses. Physis, Rio de Janeiro, v. 15, 2005. Disponível em: http://www.scielo.br/scielo. php?script=sci_arttext $\&$ pid=S0103-73312005000300005. Acesso em: 27 jul. 2009.

KUCINSKI B. Jornalismo, saúde e cidadania. Interface - Comunic., Saúde, Educ., Botucatu, SP, v. 6, p. 181-186, fev. 2000. Disponível em: http://www.scielo.br/pdf/icse/v4n6/25.pdf. Acesso em: 18 jun. 2009.

LÖWY I. Virus, mosquitos e modernidade: a febre amarela no Brasil entre ciência e política. Rio de Janeiro: Fiocruz, 2006.

MACHADO K. Lições de uma cobertura desastrosa. Revista-Radis, Rio de Janeiro, n. 69, maio 2008. Disponível em: http://www.ensp.fiocruz.br/radis/revista-radis/69/reportagens/ licoes-de-uma-cobertura-desastrosa. Acesso em: 6 out. 2008. 
MARECO R. T. M.; PASSETTI M. C. C. Greve dos professores do Estado de São Paulo: efeitos de (im)parcialidade em manchetes de dois jornais paulistas. Revista NUPEM, Campo Mourão, PR, v. 2, n. 3, p. 119-131, 2010.

POTTER J.; WETHERELL M. Discourse and social psychology: beyond attitudes and behaviour. London: Sage Publication, 1987.

SHAW E. F. Agenda-setting and mass communication theory. International Communication Gazette, v. 25, n. 96, maio 1979. Disponível em: http://xa.yimg.com/kq/ groups/22925642/1944236267/name/Shaw-+Agenda-Setting+and+Mass+Communicat ion+Theory.pdf. Acesso em: 15 jan. 2011.

SOUSA, J. P. O dia depois: a reacção da imprensa portuguesa ao atentado de 11 de marco de 2004 em Madrid. In: GOMES A. (org.). Além da notícia. Natal: Edufrn, 2006.

SPINK M. J.; MEDRADO B. Produção de sentidos no cotidiano: uma abordagem teórico-metodológica para análise das práticas discursivas. In: SPINK M. J. (org.). Práticas discursivas e produção de sentidos no cotidiano: aproximações teóricas e metodológicas. 3. ed. São Paulo, SP: Cortez, 2004.

SPINK, P. K. Análise de documentos de domínio público. In: SPINK, M. J. (org). Práticas discursivas e produção de sentidos no cotidiano: aproximações teóricas e metodológicas. São Paulo, SP: Cortez, 2000.

TAUIL P. L. Aspectos críticos do controle da febre amarela no Brasil. Rev. Saúde Pública, São Paulo, v. 44, n. 3, p. 555-558, 2010. Disponível em: http://www.scielo.br/pdf/rsp/ v44n3/20.pdf. Acesso em: 13 fev. 2011.

VASCONCELOS, P. F. C. Febre amarela. Rev. Soc. Bras. Med. Trop., Uberaba, MG, v. 36, n. 2, p. 275-93, mar./abr. 2003.

WOLF M. Teorias da comunicação. 5. ed. Lisboa: Presença, 1999.

WORLD HEALTH ORGANIZATION - WHO. Yellow fever in Brazil (Global alert and response). Genebra, 5 fev. 2008. Disponível em: http://www.who.int/csr/don/2008_02_07/ en/index.html. Acesso em: 13 abr. 2011.

\section{Notas}

${ }^{1}$ Este artigo é resultado de dissertação de mestrado, apresentada em outubro de 2011, e não apresenta conflitos de interesse.

2 Processo de midiatização é o deslocamento de um dado acontecimento do cotidiano para o foco de interesse da mídia, consequentemente, sua configuração como notícia que media o espaço público e constrói a realidade social.

${ }^{3} \mathrm{O}$ jornal Folha de S.Paulo conta com duas edições impressas diárias: a Edição SP, que circula na Grande São Paulo, à exceção do ABCD paulista; e a nacional, disponível nas demais regiões do país. São disponibilizados também cadernos locais, produzidos por equipes regionais, que abordam temas de interesse exclusivo dessas áreas de circulação. A versão digital, disponível no portal UOL, refere-se à Edição SP. 
${ }^{4}$ De acordo com o Novo Manual da Redação, 1996, no jornal Folha de S.Paulo a cobertura jornalística é dividida em editorias, cada qual responsável por campos temáticos e áreas de abrangência. $\mathrm{O}$ jornal também chama essas editorias de cadernos. Nesta pesquisa, usamos exclusivamente o termo "editoria".

${ }^{5}$ Conceito da hipótese agenda-setting que indica a relevância de um tema na pauta jornalística.

${ }^{6} \mathrm{C}$. Malinverni participou da coleta e análise de dados, da discussão dos resultados e da redação final do artigo. A. M. B. Cuenca participou da coleta e análise de dados e da discussão dos resultados. J. I. M. Brigagão participou da discussão dos resultados e da revisão teórica do artigo. 


\section{Media epidemics: sense production and social configuration of yellow fever in the journalistic coverage, 2007-2008}

Located in the Field of communication and health, the objective of this article is to analyze the senses attributed in the discourse on yellow fever, during the journalistic coverage of the epizooty of the diseased, occurring in Brazil during the summer 2007-2008. Employing the theoretical reference of discursive practices and sense production in daily life and the hypothesis of agendasetting and framing of the news, all material on yellow fever issued by the newspaper "Folha de São Paulo" were analyzed during the period comprised between 12/21/07 to $02 / 29 / 08$ as well as all official documentation on the epizooty issued by the Brazilian authorities on public health during the period comprised between $01 / 03$ and $02 / 28 / 08$. Finding indicate that discursive strategies of the journalistic coverage rendered relative the discourse of public health authorities; prioritized divulgation of the number of cases; emphasized vaccination as the limit between life and death, refraining to inform the risks of the indiscriminate use of the product and propagated the imminence of a major epidemics of yellow fever. These strategies attributed new senses to the disease, dislodging the event from the wild form, restrict in space and limited in severity, to the urban form, characterized by epidemics and with a more severe potential. Secondarily, this study allowed to identify the impact of this media discourse on the national immunization system and the risks to which the population was exposed due to the senses produced: in 2008, eight cases of serious reactions to the vaccine were registered, and six of these cases resulted in deaths.

> Key words: Yellow fever; journalism; communication in health; discursive practices; agenda-setting; framing. 